\title{
REHAB FUN: an assistive technology in neurological motor disorders rehabilitation of children with cerebral palsy
}

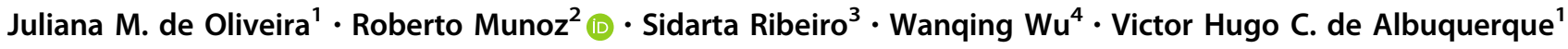

Received: 26 September 2018 / Accepted: 23 January 2019

(C) Springer-Verlag London Ltd., part of Springer Nature 2019

\begin{abstract}
Cerebral palsy is a childhood condition in which there is a motor disability (palsy) caused by a static, non-progressive lesion in the brain (cerebral), produced by decreased brain oxygenation during pregnancy at birth or soon after birth. The rehabilitation of patients with disabilities such as cerebral palsy is usually accomplished through exercises performed by a team of several specialists so that the patient can act independently or minimize the need for third parties. The virtual reality environment called REHAB FUN was developed as a purpose to aid in the treatment of patients with cerebral palsy from 3 to 8 years. The REHAB FUN is composed of 10 phases (activities) and a web area for analysis of the specialists to follow the evolution of the patients. Seven patients were participated using the virtual environment twice a week for 3 months (20 sessions). We measured attention levels, errors, and time. The REHAB FUN has been shown to be a motivating tool for patients, and through the data acquired, the specialists can direct the treatment in an individualized way so that there are greater effectiveness and efficiency in the treatment of motor rehabilitation.
\end{abstract}

Keywords Cerebral palsy $\cdot$ Assistive technology $\cdot$ Brain-computer interface

\section{Roberto Munoz \\ roberto.munoz@uv.cl \\ Juliana M. de Oliveira \\ jullianamartins@edu.unifor.br \\ Sidarta Ribeiro \\ sidartaribeiro@neuro.ufrn.br \\ Wanqing $\mathrm{Wu}$ \\ wq.wu@siat.ac.cn}

Victor Hugo C. de Albuquerque

victor.albuquerque@unifor.br

1 Graduate Program in Applied Informatics, Laboratory of Bioinformatics, University of Fortaleza, Fortaleza, CE, Brazil

2 Escuela de Ingeniería Civil Informática, Centro de Investigación y Desarrollo en Ingeniería en Salud, Universidad de Valparaíso, Valparaíso, Chile

3 Brain Institute, Federal University of Rio Grande do Norte (UFRN), Natal, RN, Brazil

4 CAS Key Laboratory of Human-Machine IntelligenceSynergy Systems, Shenzhen Institute of Advanced Technology-Chinese Academy of Sciences (SIAT-CAS), Shenzhen 518055, China

\section{Introduction}

Cerebral palsy (CP), one of the diseases that causes motor deficiency, is a childhood condition in which there is a motor disability (palsy) caused by a static, non-progressive lesion in the brain (cerebral) $[10,15,16]$, caused by decreased brain oxygenation during pregnancy at birth or soon after birth. The rehabilitation of patients with $\mathrm{CP}$ is usually accomplished through exercises performed by a team of several specialists so that the patient can act independently or minimize the need for third parties. Although in general this disability is present throughout the life of the individual, for some skills it is more susceptible at the beginning of development [2].

$\mathrm{CP}$ is often classified by severity level as mild, where a child can move without assistance; his or her daily activities are not limited. Moderate means a child will need braces, medications, and adaptive technology to accomplish daily activities, and severe, in which the child will need a wheelchair and will have significant challenges in carrying out daily activities. These broad generalizations lack a specific set of criteria [6]. The type of CP and its severity is dependent on the affected area of the brain. 
The rehabilitation process depends mainly on numerous stimuli so that the patient feels motivated and perceives the importance of the proposed treatment through the perception of its evolution throughout the treatment [26]. Virtual reality (VR) is a computational technology that provides artificial sensory feedback, allowing a user to experiment activities and events similar to those that could be found in real life, and to develop motor abilities in three-dimensional (3D) virtual environments that resemble the real world accordingly [16]. VR involves three key elements that are required for motor learning: (1) repetitions, because neural plasticity is dependent on repeated stimulation, which is able to produce optimal learning; (2) sensory feedback, because intense multisensory stimulation is an essential part of rehabilitation for children with cerebral palsy, a systemic disease; and (3) motivation of the patient [19].

Several studies using VR for treatments of neurological dysfunctions are being performed and already demonstrate satisfactory results regarding the evolution of the motor and cognitive development of patients of different ages [5, 23]. In most cases, the environment was based on games (serious game or exergames) applied to sensorimotor processing. The results are overall very promising, mainly due to the abstraction of traumatic symptoms such as pain and fear, to the escape from the real world, and to the incentive to overcome the challenges posed by virtual environments.

The use of leap motion to control the movements of activities performed in virtual environments has presented significant results when applied to rehabilitation treatments of upper limbs. The use of these technologies can be found in the rehabilitation of stroke patients [13, 20, 32] and [8].

For the treatment of children, some adaptations or rehabilitation games applied to entertainment games can be highlighted [9, 11, 12, 14, 28, 30] and [25]. In the proposal addressed in the non-immersive virtual environment "REHAB FUN," the suggestion of its use as an additional auxiliary tool to the treatment performed for neuropsychomotor rehabilitation of children with $\mathrm{CP}$ between 3 and 8 years are presented. It aims to improve motor and cognitive abilities from activities of relation between forms, colors, and objectives according to the interest of the informed age group. It provides arm and hand extension and flexion exercises to reduce contraction and rigidity of the musculature caused by paralysis and additionally improve the fine motor skills of upper limbs through the use of leap motion [24].

This sensor is able to capture movements of the 10 fingers of the hands, without the intervention of a device attached to the patient's body, bringing a greater degree of freedom. In order to measure the evolution of the patient through the use of the virtual environment during treatment, the level of attention in real time is measured from attention-related beta waves through the EEG MindWave.

Another reason for the growing use of this type of treatment is the enhanced attractiveness of interactive environments and to the challenges posed by the game in pursuit of conquests/rewards (positive reinforcement) following the conclusion of a specific task [4].

The development of serious games using VR aims to provide a playful environment for use in the rehabilitation treatment of children who present neurological dysfunctions to stimulate cognition and movement of the upper limbs, aiming to accelerate the rehabilitation process by stimulating neuroplasticity or plasticity $[1,18]$.

Additionally, it is possible to follow the evolution of the patient through reports containing data related to attention, time, and errors collected during the activities through the virtual environment and EEG MindWave. In addition, because it is a virtual environment that uses tools easily found in the market (leap motion and MindWave) it is possible to use in various environments such as offices, homes, and schools.

In this paper, we present the results in the use of "REHAB FUN" in the Neuro Psychomotor Rehabilitation Program of the Integrated Medical Care Center at the University of Fortaleza-Ceará Brazil. REHAB FUN was used for five months with seven children diagnosed with $\mathrm{CP}$, presenting promising results. The present work is divided as follows: In Sect. 2 we show the methodology highlighting the group of children with CP. The proposed tool and the architecture of the applications used for the remote control are presented in Sect. 3. The results are analyzed and discussed in Sect. 4, and finally, the conclusions and future work are discussed in Sect. 5.

\section{Materials and methods}

As shown in Fig. 1, the methodology is divided into 6 stages that make up the actions performed in the following paper. The first step of the defined methodology involves the activities performed in the analysis of the neurorehabilitation programs with potential applicability in the use of virtual environments as complementary therapeutic tools; the second step contemplates which activities to implement in the virtual environment and how they will be selected; the third step presents how the development of the virtual environment is developed, which tools are utilized, and the technology and integrations realized; fourth step presents the necessary steps to define selection criteria for patients as well as appropriate authorizations from those responsible for said patients; fifth step details the procedures of the applicability of the virtual environment as a 


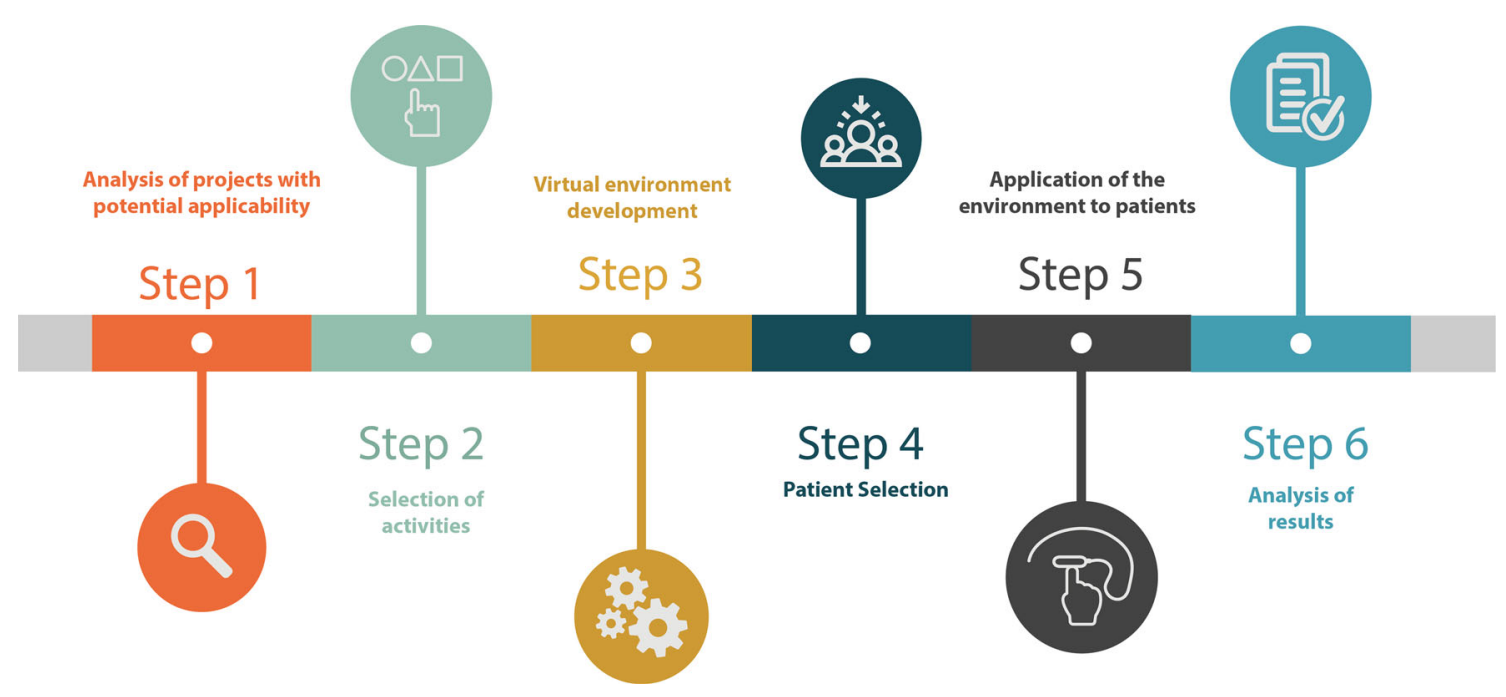

Fig. 1 Work methodology

complementary tool for traditional treatment (or approach) in the chosen program; lastly, sixth step presents the techniques utilized to analyze the collected data during the use of the virtual environment.

In step 1-Analysis of neurorehabilitation programs with potential applicability-visits were realized over a period of 1 month in an observatory manner to neurorehabilitation programs that treat patients with neurological dysfunctions in the NAMI center (Integrated Medical Care Center). The objective of this was to establish contact with the affected children as well as with different specialists associated with neurorehabilitation. These activities were realized in order to posteriorly determine, in conjunction with the specialists, the correct intervention program.

In step 2-Selection of activities-professionals (physiotherapists, psychologists, and occupational therapists) from health-related fields were consulted on which activities should be modeled within the virtual environment. These activities were divided into different levels to incentivize the child to continually work toward a proposed objective. Ten stages were suggested by the specialists along with an objective for each one, such as which movements to perform. In agreement with [29], these can be very simple movements, i.e., flexing arms, legs, or touching an object. These activities were categorized by topics and are resumed in Fig. 2.

In step 3-Development of the virtual environmentdecisions were made associated with development, such as the architecture definition, which tools, and which programming language to use. The platform REHAB FUN was divided into two applications. The first is associated with a web platform, and the second is associated with a desktop application. The web platform was developed for the visualization of reports, graphs, and an administrative area for managing records of institutions, patients, and professionals. Furthermore, the virtual environment was developed integrating 2 technologies. The first deals with the leap motion sensor, the objective being that the interaction between the child and the device should be natural. The second is related to the MindWave headset; the purpose of using this was to determine the attention levels of the child (patient) at the moment of using the developed environment.

In step 4-Patient selection-subjects were selected that participated in complementary activities (to their primary treatment plan) utilizing REHAB FUN. This selection was realized by professionals in Occupational Therapy, Physiotherapy, Speech Therapy, and Psychology, second [31]. The patients were selected from the psychomotor neurorehabilitation program. Ages ranged from 3 to 8 years old, and the patients selected were diagnosed with cerebral palsy. The defined criteria for the selection of patients involved were that the complementary treatment did not interfere with the evolution of the patients primary rehabilitation. Furthermore, the following criteria were considered when selecting patients: absences of hypersensitivity to light, making coarse movements, regularity to treatment, acceptance of new therapeutic approaches, stable clinical status, group of ages between 3 and 8 years old, and mild-to-moderate CP levels. For this reason, the types of cerebral palsy present in this study were hemiplegia, which affects one side of the body (leg, trunk, and arm), and diplegia, which affects both arms and both legs [2].

In step 5-Application of virtual environment as a complementary tool-in agreement with the planning of activities of the virtual environment, it was defined that interventions would be $15 \mathrm{~min}$ in duration 2 times a week for 3 months. The activities would be realized after the neuropsychomotor rehabilitation sessions. Furthermore, 


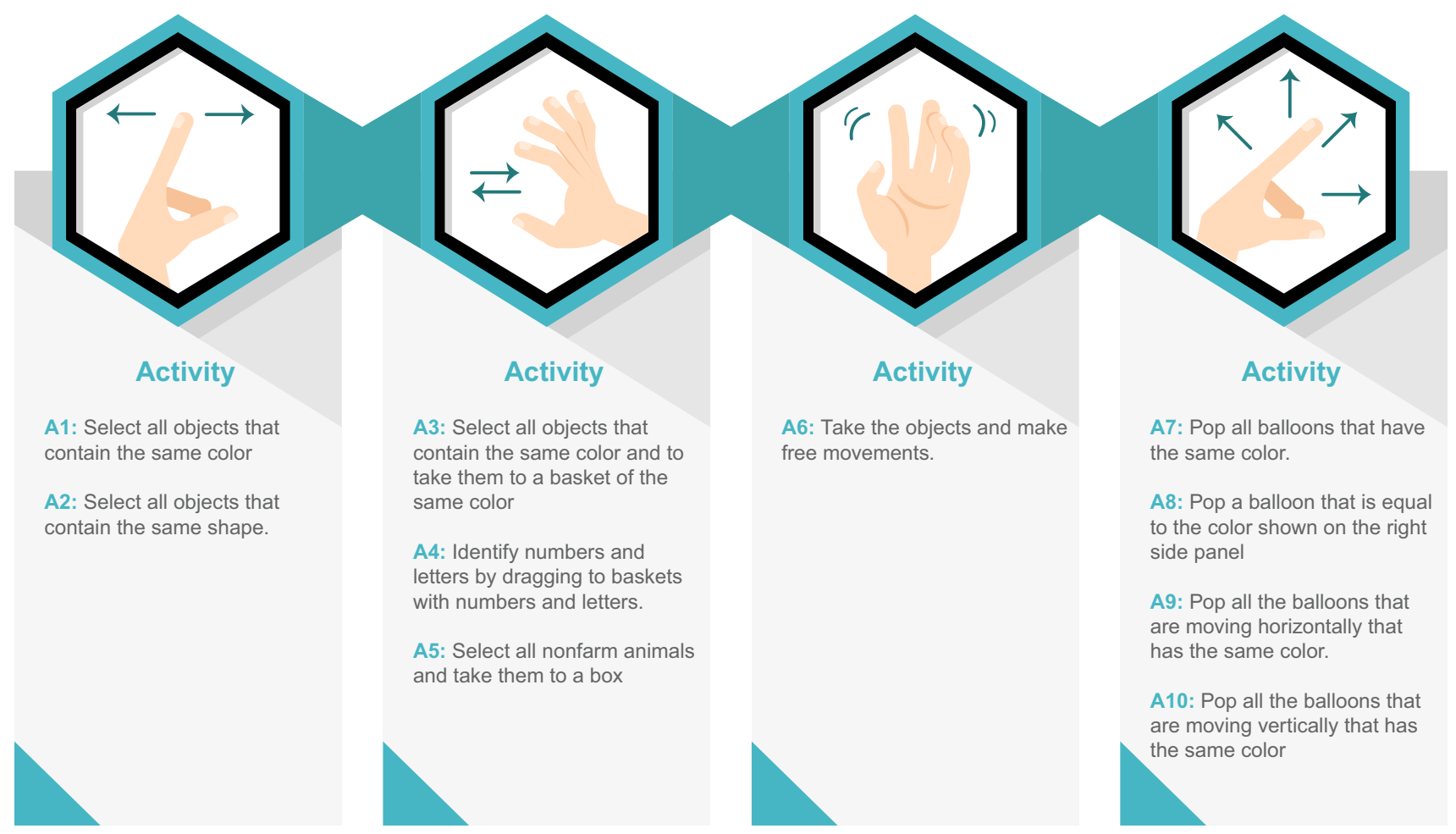

Fig. 2 Developed activities

during this time (15 $\mathrm{min})$, approximately $3 \mathrm{~min}$ is accounted for the preparation of the patient, such as when the MindWave is placed on the head, opening the patient session in the virtual environment, positioning the leap motion sensor in relation to the patient, and the execution of the activities.

Each activity was organized in the following manner: The activity is presented on the first day, and the patients are asked to use their most functionable hand to complete the learning of movement and the understanding of the objective of each activity. After the patients complete this first activity, they are asked to repeat the activity again with the hand affected by the cerebral palsy. The next day, they are asked to repeat the previous activity using the hand affected by the CP, and after this stage a new activity is presented in which the process is repeated. It is important to highlight that this work was approved by the Research with Human Beings Ethics Committee of the University of Fortaleza (UNIFOR) (CAAE-75563417.0.0000.5052).

Lastly, in step 6-Analysis of results-the collected data from the complementary activities that utilized the virtual environment, and which was saved in a database, is presented. This analysis was based on characteristics of the patient, such as type of paralysis, behavioral status, which activities were completed with difficulty and those with ease, and feelings in relation to the proposed activities. This was realized by triangulating the observed behavior and behavior captured by the system, i.e., attention level, quantity of errors, time used in each activity. To do this, the data were analyzed by using $t$ Student, which normalized the parameters analyzed.

\section{Architecture}

To develop the system architecture (see Fig. 3), in agreement with the established criteria in stage 3 of the methodology (development of the virtual environment), the need for the development of two integrated systems was identified. The first is related to the implementation of a serious game, REHAB FUN, which was developed through the Unity engine. The second system is related to web development for patient registration, institutions, responsible parties of patients, and follow-up of the results obtained in the interventions with REHAB FUN and the patient through charts and reports.

The system developed with the Unity engine is integrated with leap motion, with which it captures the movements of the hands, and MindWave, with which the level of attention is captured during the execution of the activities by the patient. The developed system also has integration with the web platform via Web API for bidirectional communication of the data circulating between the virtual environment and the web system. The generated data are stored locally and synchronized routinely and replicated to a WEB server. 
Fig. 3 Work methodology

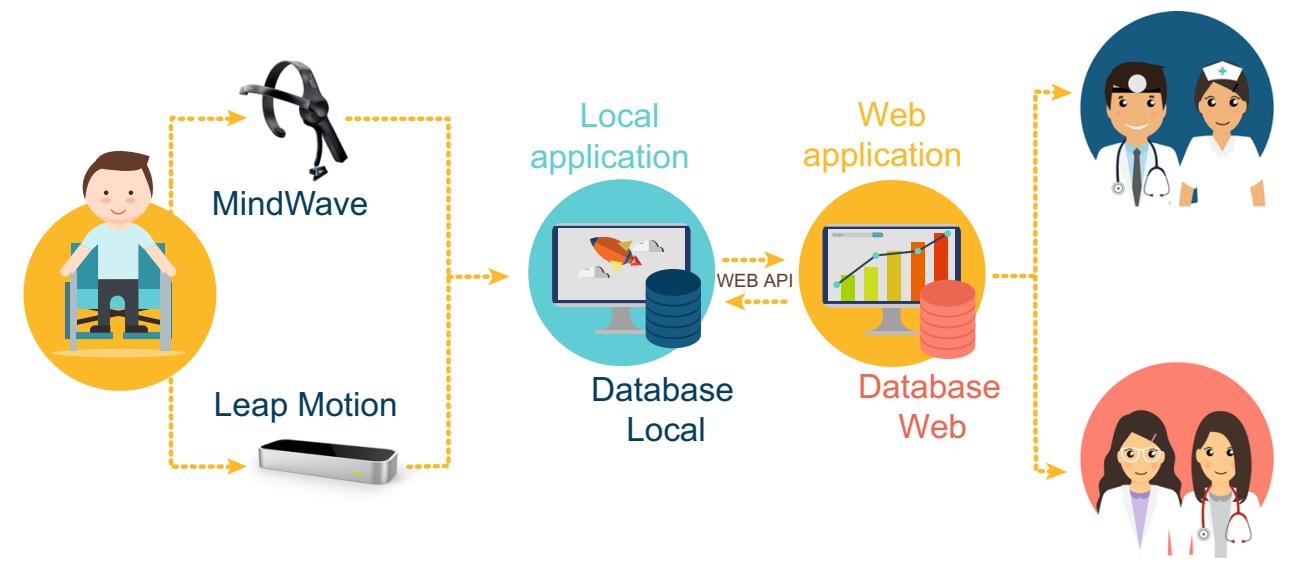

\subsection{Leap motion}

The leap motion device is responsible for the interaction of the user with the virtual environment, capturing the movements of the hands. Its principal advantage is the liberty of movement of the superior extremities, due to the fact that to capture movement a device does not need to be worn on the body. Finally, the connection with the virtual environment uses the core assets 2.2.2 SDK. Above, Algorithm 1 shows the moves returned by the SDK.

Algorithm 1 Movements purchased by the SDK

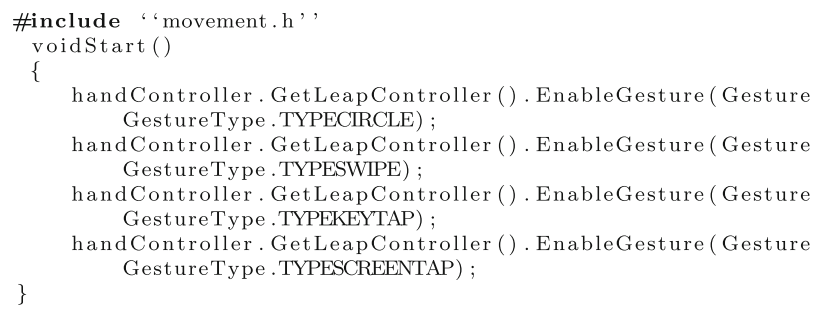

\subsection{MindWave}

Within the proposed system, MindWave is equipment of non-obligatory use. This device is responsible for measuring electrical analogue signals, commonly referred to as brainwaves, and transforms them into digital signals. In this virtual environment, it is responsible for capturing low beta waves in the interval of $12-15 \mathrm{~Hz}$, midrange beta waves in the interval of 16-20 Hz, and high beta waves in the interval of $21-30 \mathrm{~Hz}[17,21]$.

These waves are captured in each phase (per second) and are presented by percentages at the end of each stage, along with the average of attention related to each activity. The beta frequencies, whose values range between 12 and $30 \mathrm{~Hz}$ per phase, correspond to a 0 and $100 \%$ of attention, respectively.
In order for the data to be sent to the virtual environment, the API socket ThinkGear Connector (TCG) was used, running in the background and thus communicating between MindWave and REHAB FUN. The wave catch is given as shown in Algorithm 2 [22]:

Algorithm 2 Creating the MindWave-computer connection

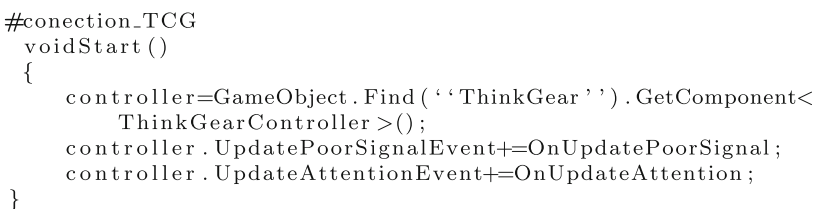

\section{Results and discussion}

The project chosen for intervention in the NAMI (Núcleo de Atenção Médica Integrada) is part of the occupational therapy program called Neuroreabilitao Psicomotora. This project acts in the rehabilitation of children from 0 to 8 years old with neurological dysfunctions, such as microcephaly, head trauma, and cerebral palsy. In total, 7 subjects ( 4 boys and 3 girls) between 3 and 8 years old (M: 5.5 years, SD 0.58 years) were selected to participate in this initiative.

All selected subjects participated in the psychomotor rehabilitation program since the first year of life. Furthermore, subjects had external stimuli through the school they attended and other physical and cognitive stimuli such as swimming and school reinforcement, among others. The sessions were held during a period of 3 months, each session lasting $15 \mathrm{~min}$ in duration, occurring 2 times a week and held after the patient's primary treatment activities. 


\subsection{Web interface}

To assist the experts, a web platform has been developed, where the specialist can register the patient, their caregivers and monitor their progress as shown in Fig. 4 where (a) is related to expanded side menu, (b) list of patients with data obtained through the virtual environment with patient name, phases, time, error, attention, and the hand used during the phase, and (c) the graphics related to data present above.

It was developed in the front-end layers in Angular 6 and Bootstrap 4 and the back-end layer within the creation of services, authentication, and control.

For the authentication in the virtual environment and website, we have used Bearer authentication. Bearer authentication is an HTTP authentication scheme that involves security tokens called bearer tokens. This token must be sent in the request header. Algorithm 3 is an example of a request:

Algorithm 3 Authentication header

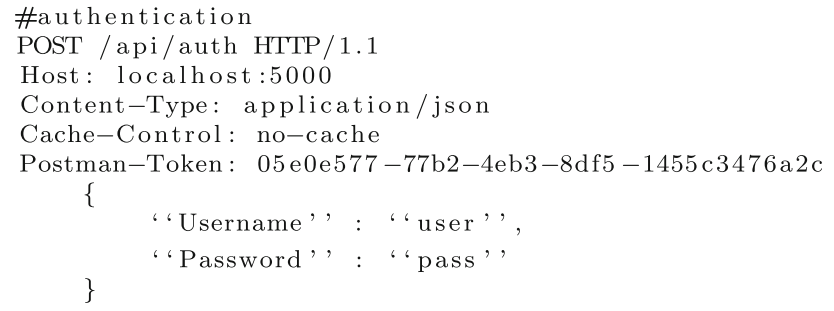

Fig. 4 Report per subject

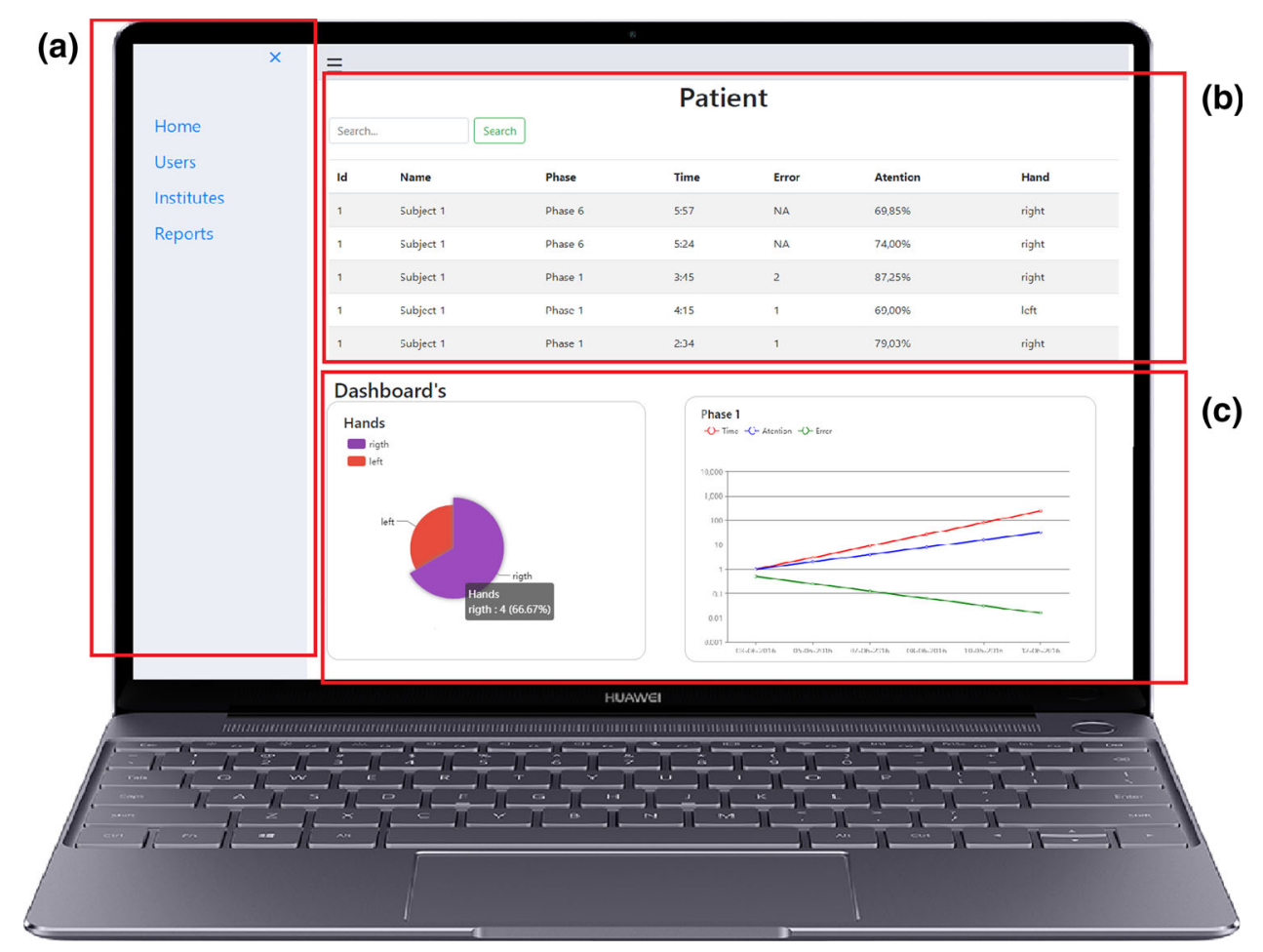

A return message will be obtained containing the access token. An example of an answer to authentication is presented in Algorithm 4:

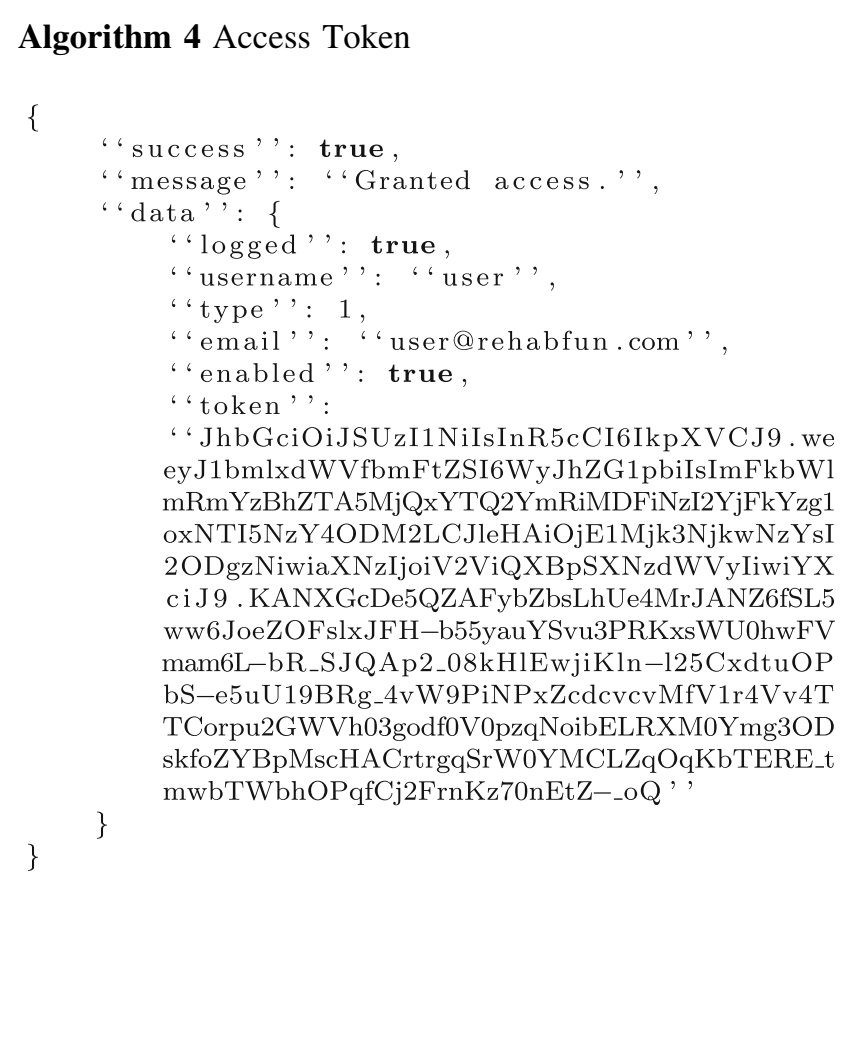

\section{Fig. 4 Report per subject}




\subsection{Virtual environment}

The REHAB FUN virtual environment was developed in C\# through the Unity engine in version 5.2.2 with MindWave integrations through the ThinkGear Connector, leap motion through the SDK, and Web Site via WEB API. Figures 5 and 6 present the phases of the virtual environment.

\subsection{Results per subject}

Patients were evaluated individually considering the evolution during the phase execution in the proposed cycles. The patient's data and their values are shown by phase during the sessions. These values are related to the hand affected by the cerebral palsy. Furthermore, phase 6 was not considered for analysis, since it was only a setting phase. For that reason, no errors were considered and only the attention levels and time used were measured.

\subsubsection{Subject 1}

Subject 1 presents Hemiplegic Cerebral Palsy on the right side at a mild level. The subject is a shy teenager. She does not express verbally but communicates through gestures with her head and hands. According to experts, verbal language ability has no relation to the physical problems of subject's paralysis. For that reason, the absence of verbal language could be a product of a trauma or lack of stimulation in her development. The subject does not present difficulties in responding or executing the requested actions, and she presents a social smile when executing some activities in which she does not make mistakes. On the other hand, she swings her head positively when we asked whether she wants to continue executing the activities. The subject was absent from treatment on days 4,8 , 12 , and 15 . On the sixth day, it was not possible to measure her attention levels due to the weak Bluetooth signal of the MindWave (the device responsible for transmitting the patient's attention levels to the virtual environment). The phase 4 was executed in 3 cycles; phases 3, 8, and 10 were executed in 4 cycles; and phase 5 was executed 5 times. Due to the evolution of the patient concerning the activities completed in the virtual environment, it was possible to perform more than two cycles in these activities, where at the end of every theme execution the subject could choose the activities that she would like to be executed. In this case, phase 5 was the most preferred. The subject did not show fear, and he did not have difficulty in executing what was being proposed. Furthermore, she did not request for help to carry out the suggested movements.

Figure 7 shows the results of attention, error, and time in relation to the executed phases.

\subsubsection{Subject 2}

Subject 2 presents Hemiplegic Cerebral Palsy on the right side at a mild level. Subject 2 is very skillful, communicative, and full of self-will, doing the activities when he
Fig. 5 Phases: a Phase 1, b Phase 2, c Phase 3, and d Phase 4

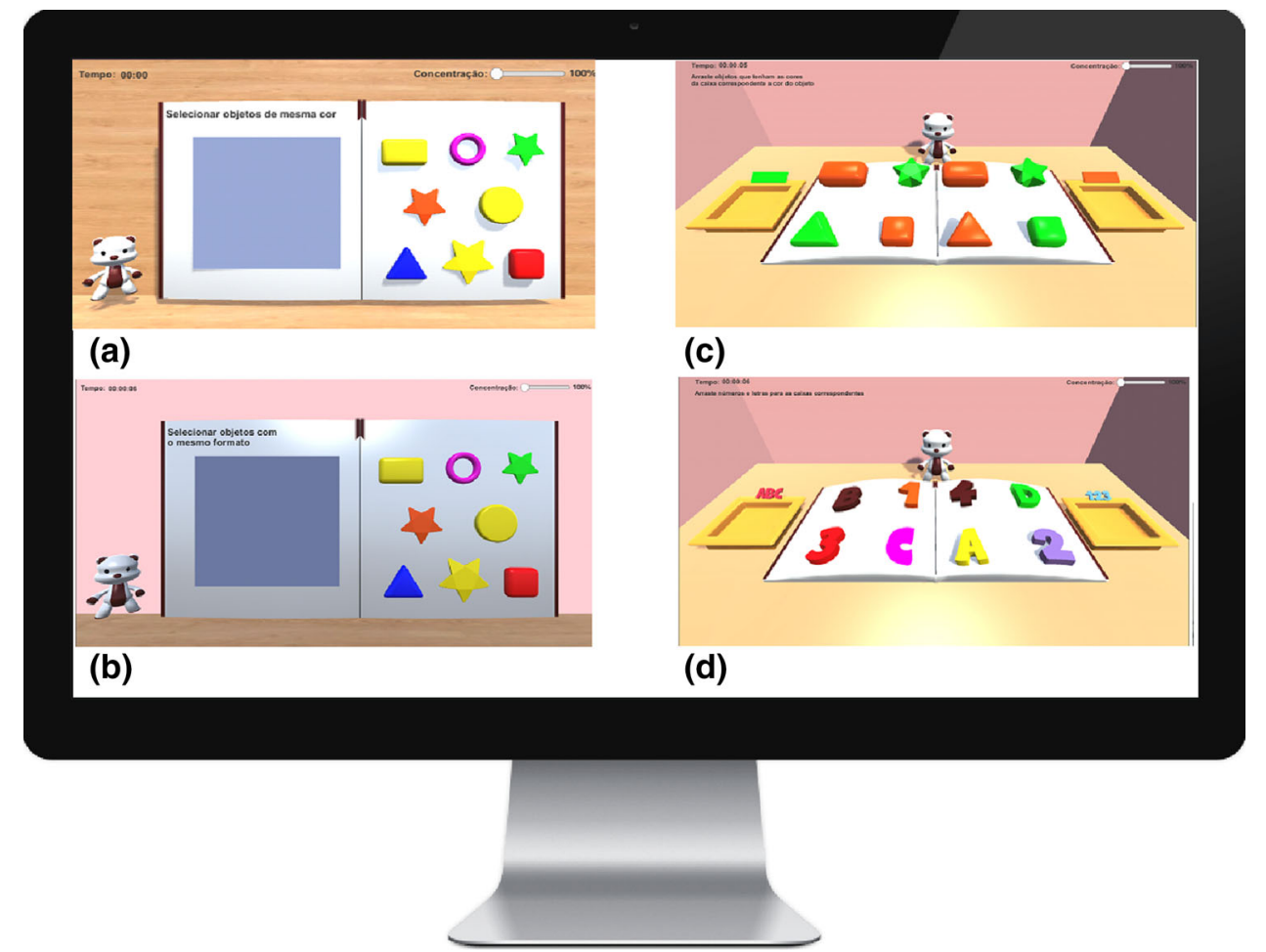


Fig. 6 Phases: a Phase 5,

b Phase 2, c Phases 7, 9, and 10,

d Phase 8

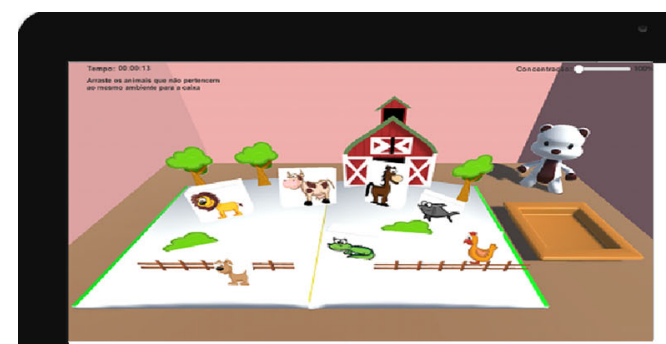

(a)

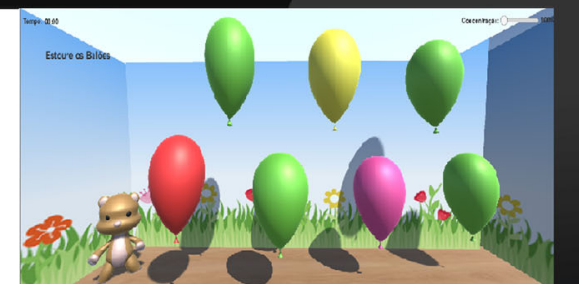

(c)

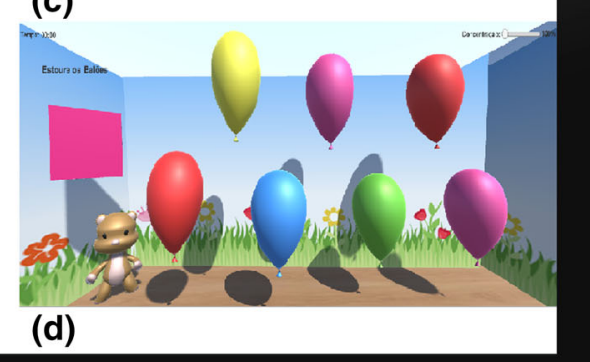

(b)

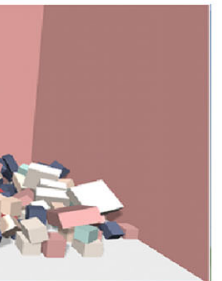

(d)

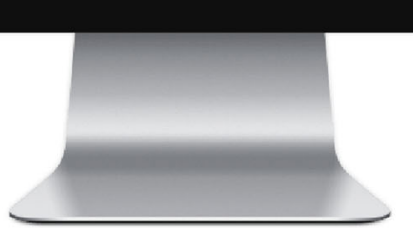

Subject 1

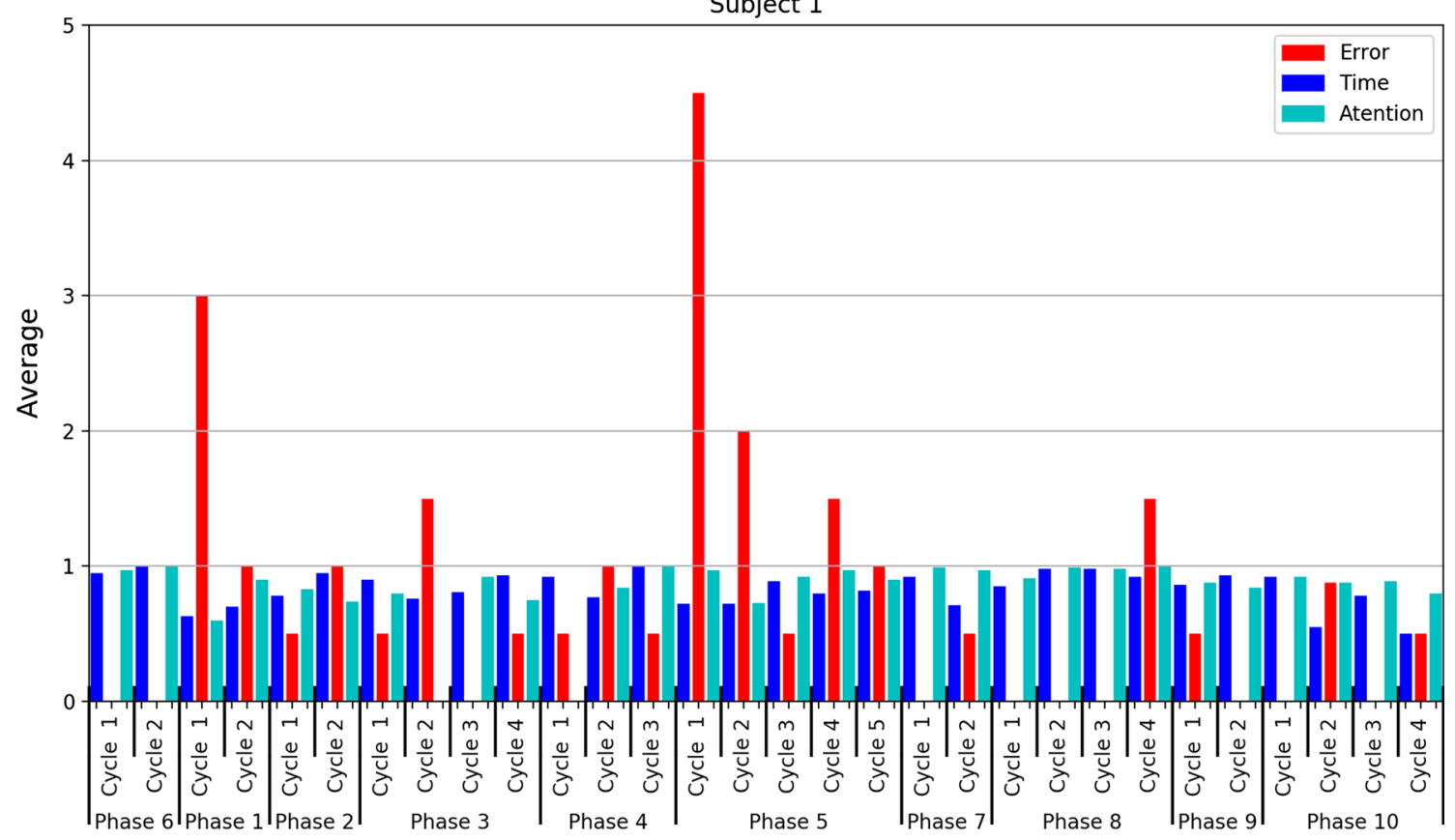

Fig. 7 Results of subject 1

feels like it. He shows gestures of affection, caressing people's faces when he does not want to perform a task or holding the hand of those individuals to execute the activities in which he should execute alone. He likes electronic devices and has a habit of playing Nintendo Wii and using a smartphone and computer when he is with his family. When using the virtual environment, the subject wants to use the leap motion as a mouse, not understanding in some moments that the hand must be above the computer without the need to touch something to exercise some activity in the virtual environment. To carry out the activities in the virtual environment, it was necessary to 
remove the keyboard and mouse from his field of view. Gabriel was absent from his treatment on days 3, 4, 11, 12, 13,15 , and 18 . The patient had many absences due to a health problem unrelated to cerebral palsy. On days 6,8 , and 19, the child could not reach the frequencies of inspection. Three cycles were performed in phases 6,7 , and 8 according to subject's request, based on the option he was given. Figure 8 shows the results of attention, error, and time in relation to the executed phases.

\subsubsection{Subject 3}

Subject 3 presents Hemiplegic Cerebral Palsy on the right side at a moderate level. Presenting speech difficulties, she smiles a lot and performs activities with help in not being able to lock the arm in the necessary position to use the leap motion. The subject was absent on the third, sixth, eleventh, and twentieth day. With this subject, it was possible to perform 3 cycles of all phases. Figure 9 shows the results of attention, error, and time in relation to the executed phases. The subject did not show fear, and she did not have difficulty in executing what was being proposed.

\subsubsection{Subject 4}

Subject 4 presents Hemiplegic Cerebral Palsy on the right side at a mild level. The subject is very charismatic and lives in another city and comes to the capital only to perform the treatment. Because of leaving very early from his city of origin to the capital, in some sessions he showed drowsiness and fatigue from daily trips. The patient was absent from treatment on days $6,11,15,19$, and 20 . For the subject, it was possible to perform 3 cycles of all phases. The patient also showed a lot of speed in the execution of the activities, but made many mistakes because he did not pay sufficient attention to what he was doing. Figure 10 shows the results of attention, error, and time in relation to the executed phases.

\subsubsection{Subject 5}

Subject 5 presents Hemiplegic Cerebral Palsy on the left side at a mild level. The subject is very communicative and when carrying out activities with the affected hand due to the paralysis, she ends, involuntarily, repeating the action with the hand that is not affected by the neurological dysfunction. He is afraid to use the hand affected by the $\mathrm{CP}$ because her caregiver (grandfather) told her that the hand was not working. During the sessions, when the subject was requested to use the left hand (hand affected by paralysis), there was visual and textual support in the execution of the actions. When the subject was asked why she did not want to use the affected hand, she related that she was afraid to use it because the hand affected by the paralysis was not working. That same speech was highlighted by the subject responsible due to the lack of patience of the person in charge, since she expected that the performance of the affected hand would be similar to the unaffected hand.

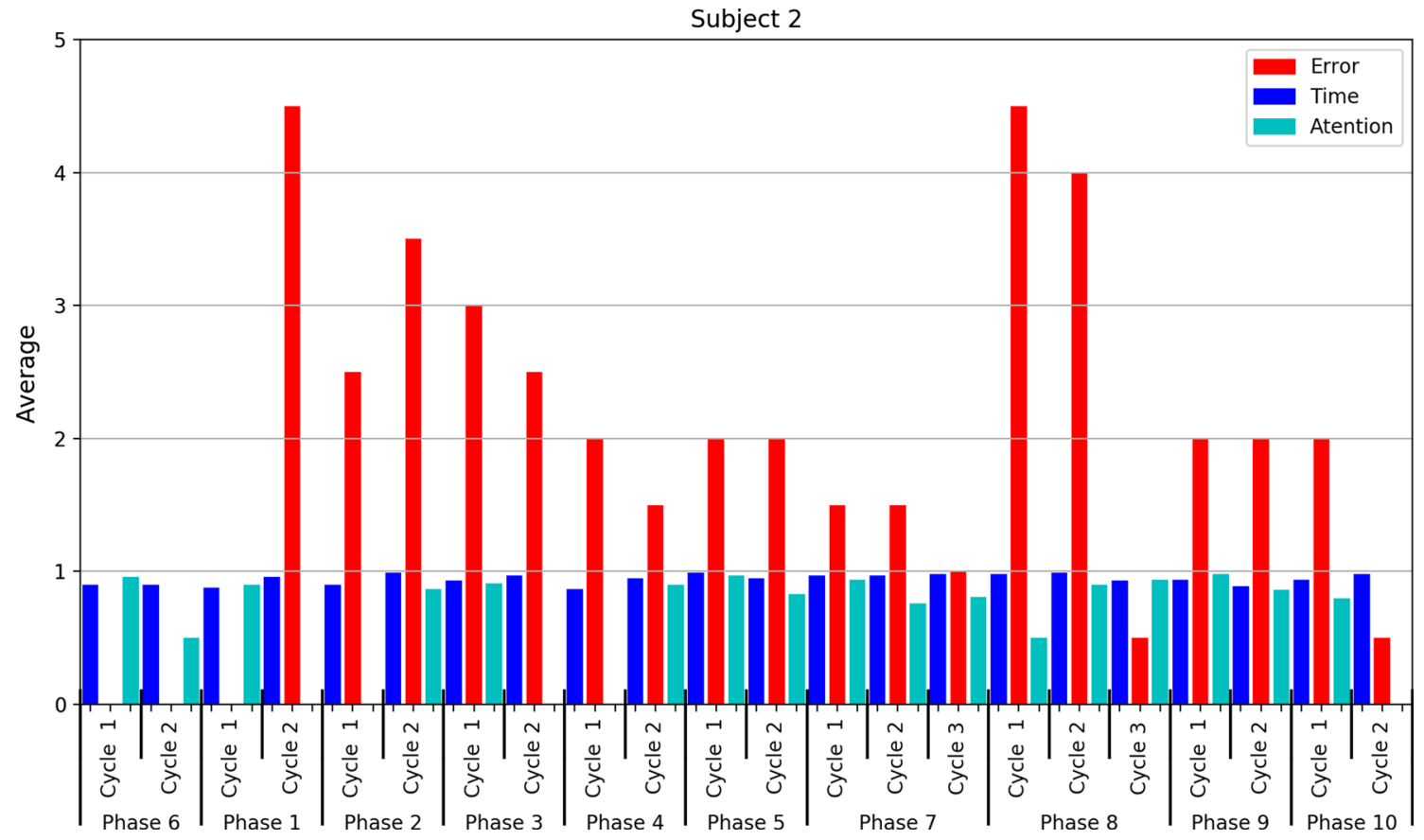

Fig. 8 Results of subject 2 


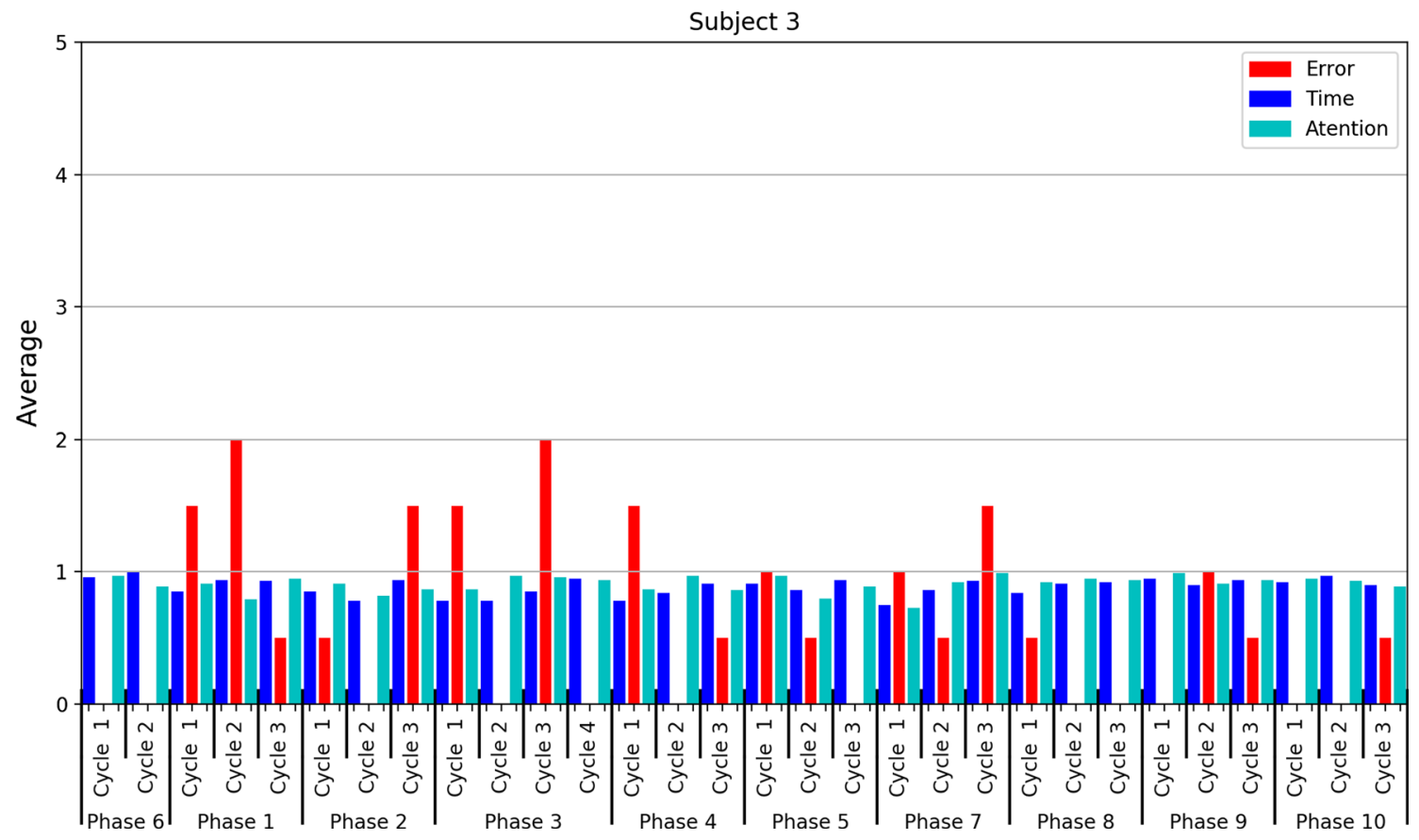

Fig. 9 Results of subject 3

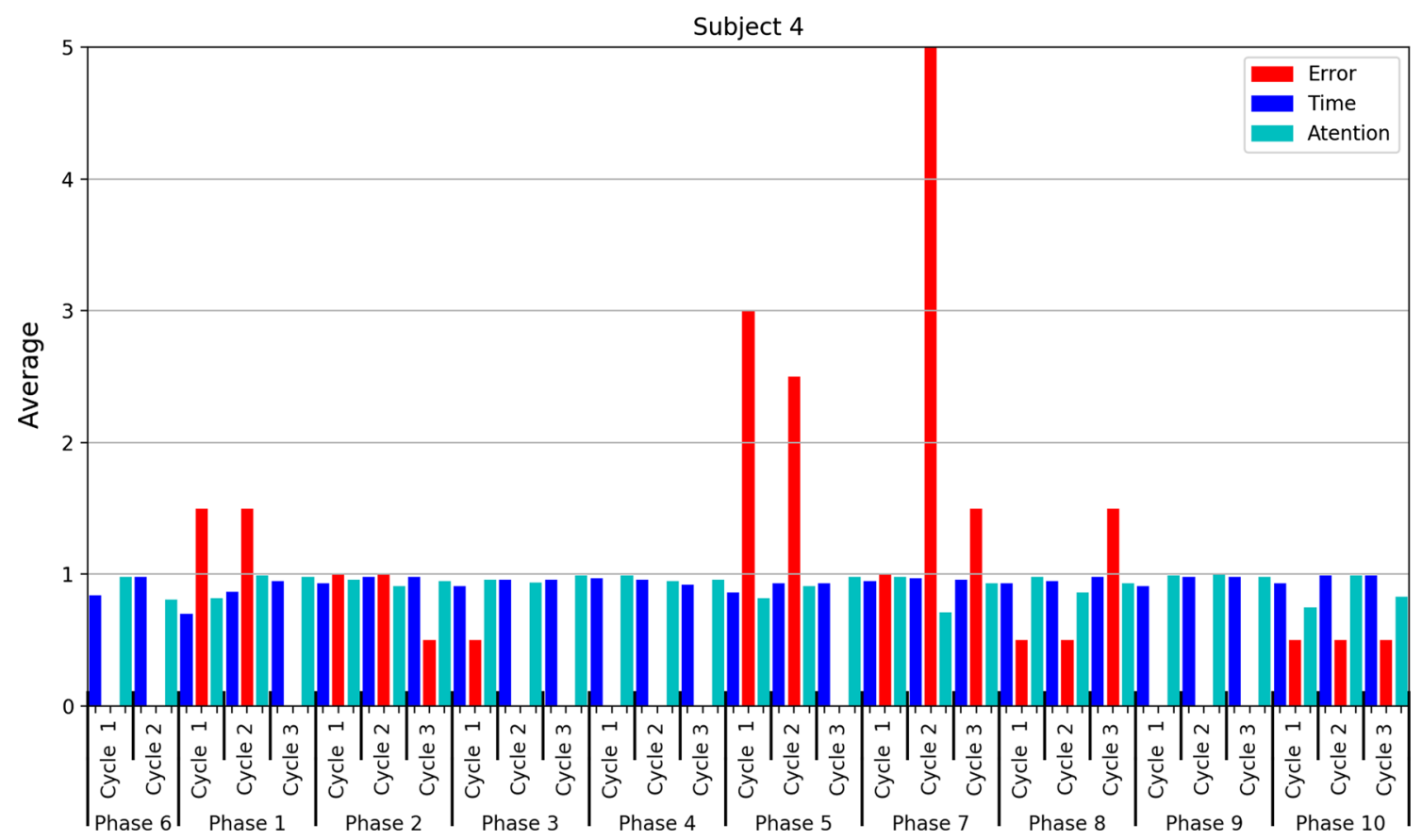

Fig. 10 Results of subject 4

It is also observed that during the activities in the virtual environment, the subject loses fear of using the hand affected by the paralysis. This is because she noticed the ability to use her hand, even with performances similar to her dominant hand (right). During the first sessions, the subject used a support element in the left hand, and after the third session the subject no longer used the support in the execution of the activities. To each success, the subject vibrated with the achievement, requesting the repetition of the proposed activity. For that particular subject it was 
Subject 5

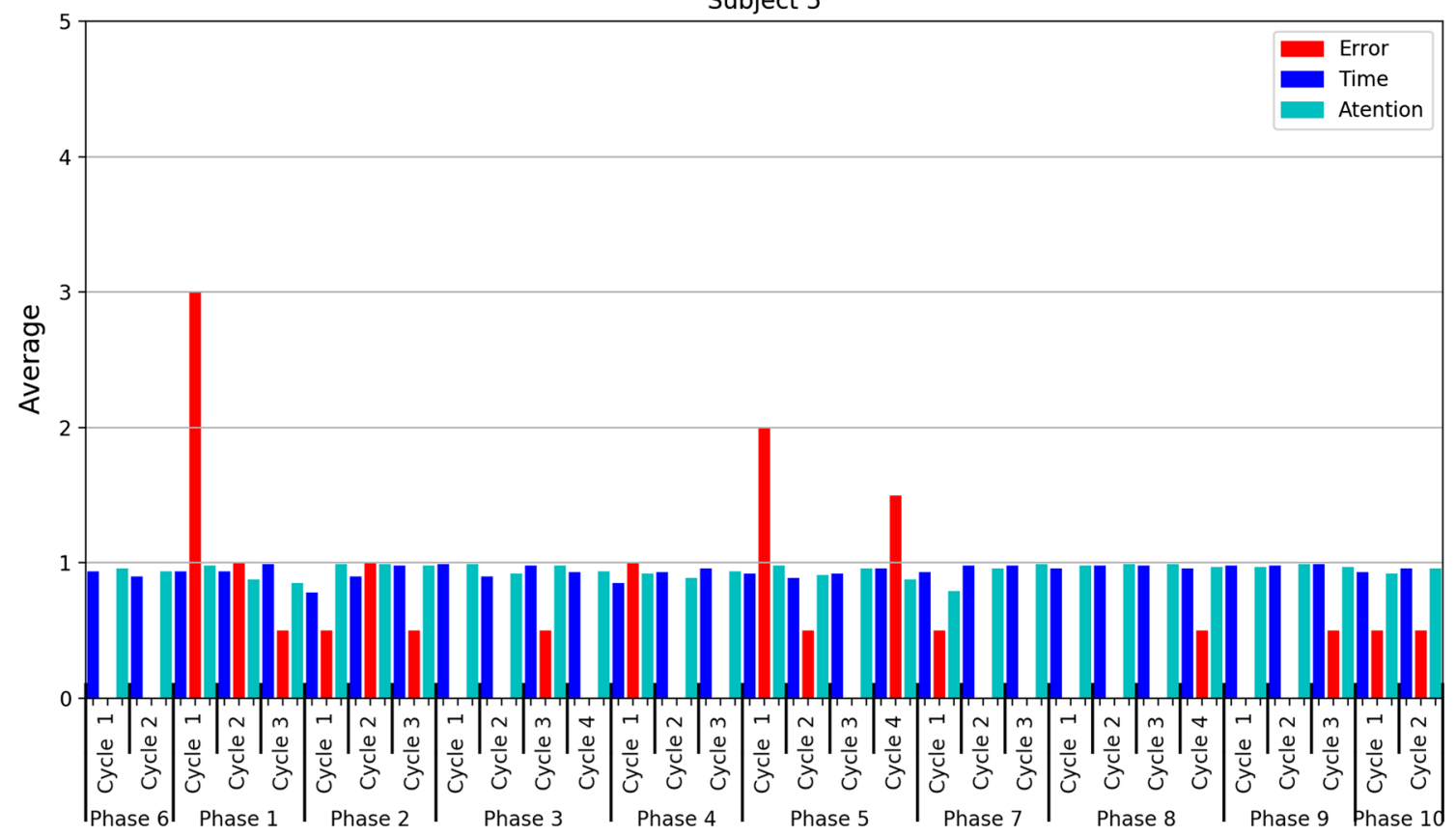

Fig. 11 Results of subject 5

possible to perform 3 cycles of all things instead of 2 cycles alone. Only for phases 3 and 8 one more cycle was carried out (day in which the subject could choose which activity she wanted to perform). The patient was absent from treatment on days $8,13,15$, and 18 . The most memorable evolution of this subject was related to the loss of fear in the use of the affected hand and the minimization of the reflex effect noticed when the subject used the hand affected by the paralysis. That is, the right hand did the same action almost involuntarily.

Figure 11 shows the results of attention, error, and time concerning the executed phases.

\subsubsection{Subject 6}

Subject 6 has mild-level Hemiplegic Cerebral Palsy. He is an adorable child and has a delay in speech, and the lower limbs are greatly compromised. It was possible to carry out all the proposed activities; he is careful in the execution of the actions that are carried out because he does not like to make mistakes and, when he is wrong, asks to repeat the activity until he stops making mistakes. He likes to show his mother that he is learning something new. The patient attended every session day. For that subject it was possible to perform 4 cycles of all phases. Figure 12 shows the results of attention, error, and time concerning the executed phases.

\subsubsection{Subject 7}

Subject 7 has Hemiplegic Cerebral Palsy on the right side at a mild level. To execute the activities, it was necessary that the specialist completes the activities themselves one time in order to be able to replicate them. Furthermore, the patient was absent between days 14 and 20 due to a scheduled surgery. Figure 13 shows the results of attention, error, and time concerning the executed phases.

To finish, not one of the patients achieved $100 \%$ of attention levels during the activities. Only one patient attended every day of therapy. Furthermore, only subject 4 did not reach the minimum concentration levels required during the activities. Subject 1 had connection problems with the MindWave due to the poor bluetooth signal. Furthermore, subject 6 achieved the highest attention levels of the activities, reaching over $98 \%$ in phase 9 . All the patients understood the proposals of the activities. The phase most executed by the subjects was phase 3 . According to data present during the validation of patients, the virtual environment can be used without negative impacts during the rehabilitation treatments and the patients. The patients presented progress in relation to the reduction of errors, the time of execution of the phases, and levels of attention comparing them individually in relation to the cycles performed. A long-term study is necessary to determine if REHAB FUN can help to accelerate the neuroplasticity process. 


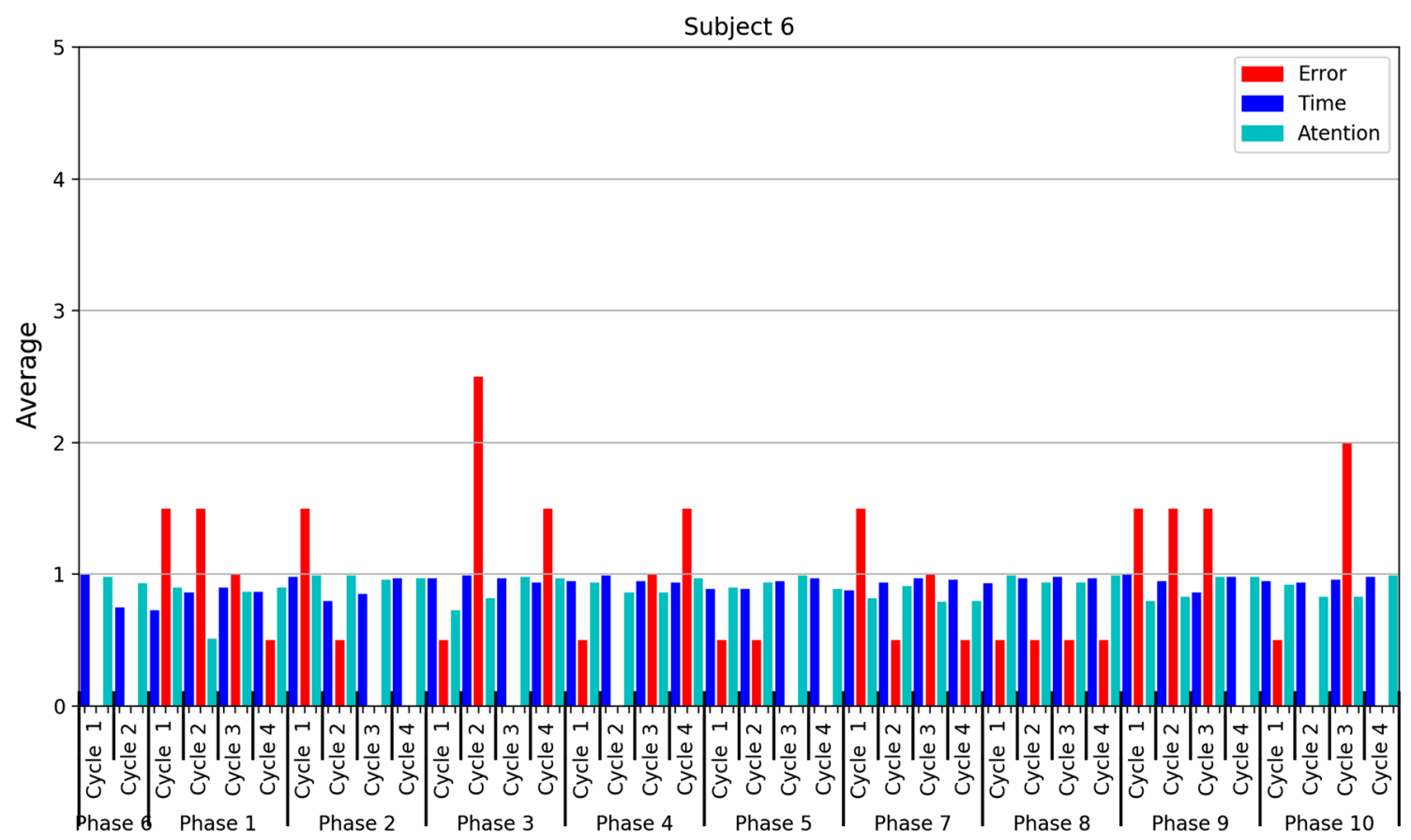

Fig. 12 Results of subject 6

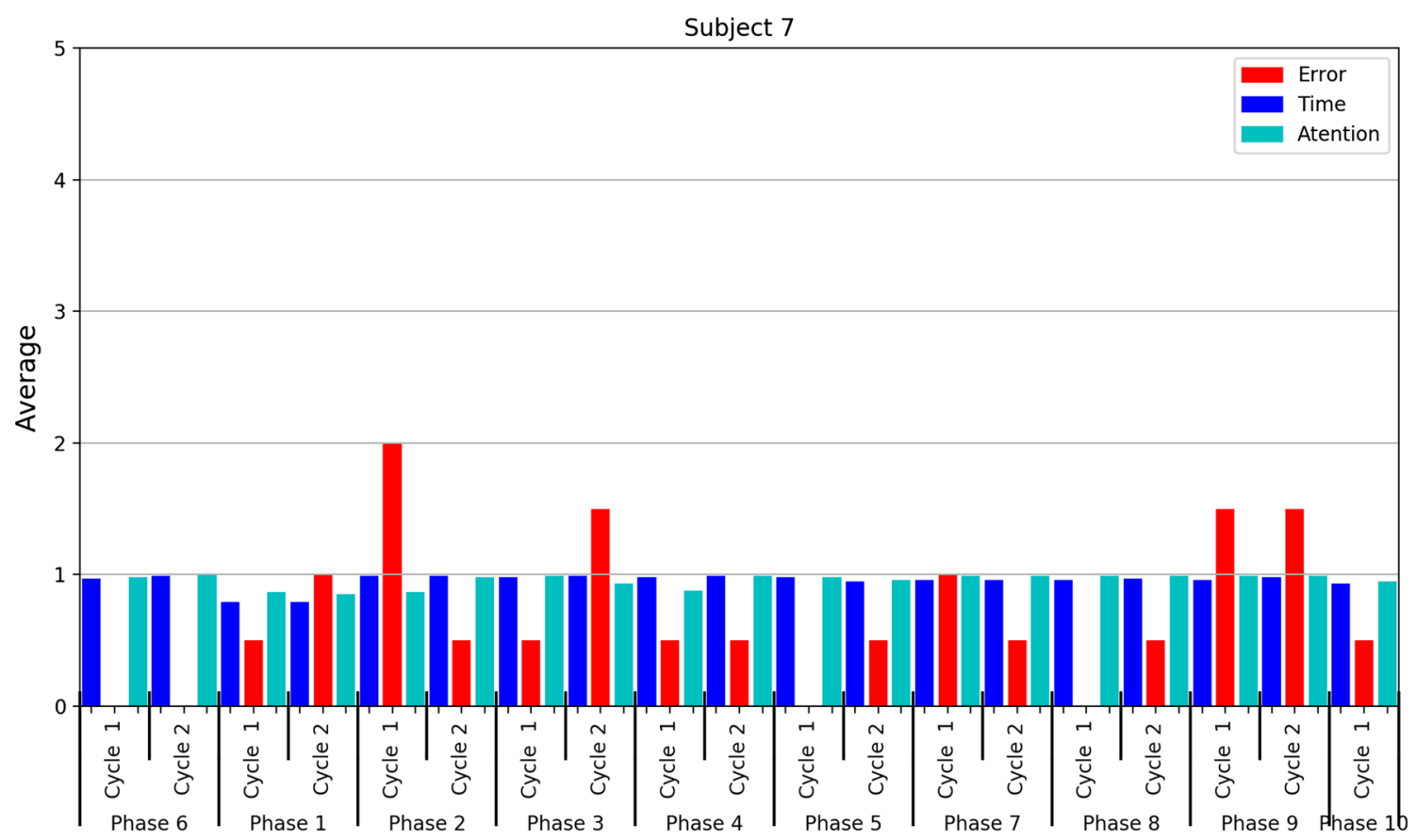

Fig. 13 Results of subject 7

\section{Conclusion and future work}

The REHAB FUN has been shown to be a motivating tool for patients, and through the data acquired, the specialists can direct the treatment in an individualized way so that there is a greater effectiveness and efficiency in the treatment of motor rehabilitation. The children were highly motivated to participate in the complementary activity, and the parents and caregivers of the patients and the specialists supported the sessions. Absences were due to patients' health or impossibility to be present on session days. Regarding the data obtained during the treatment, the 
patients tended to minimize the amount of errors, their levels of attention, and time showed with few variations. MindWave had problems connecting only one child.

The web interface, where specialists can manage patients through patients' registers and monitor evolution through graphs and reports, adds value to the specialist and brings greater freedom in the way they work, because they can centralize the information of all their patients who participate in this program regardless of their institution or geographical location. A longer period of use of REHAB FUN should be considered to prove the real effectiveness of this environment as a complementary tool to the treatment of motor rehabilitation of children.

As future work, we are going to use the IoT (Internet of Things) to measure the physiological functions of patients, understanding the stimuli of the human body and the reflection of its actions through physiological data, as [3] and [27], to apply machine learning for the virtual environment to suggest activities for patients according to their performance according [7], neurofeedback and protocol of hands.

Acknowledgements The authors thank specialists of the NAMI (Ncleo de Ateno Mdico Integrado)/UNIFOR for their support, dedication, and interest in the development and application of the proposed virtual environment. Victor Hugo C. de Albuquerque and Juliana Martins de Oliveira received support from the Brazilian National Council for Research and Development (CNPq, Grant 304315/2017-6) and Cearense Foundation for Scientific and Technological Development Support (FUNCAP), respectively.

\section{Compliance with ethical standards}

Conflict of interest The authors declare that there is no conflict of interest regarding the publication of this article.

\section{References}

1. Barzilay O, Wolf A (2013) Adaptive rehabilitation games. J Electromyogr Kinesiol 23(1):182-189. https://doi.org/10.1016/ j.jelekin.2012.09.004

2. Bax M, Goldstein M, Rosenbaum P, Leviton A, Paneth N, Dan B, Jacobsson B, Damiano D (2005) Proposed definition and classification of cerebral palsy. Dev Med Child Neurol 47(8):571-576. https://doi.org/10.1017/s001216220500112x

3. da Cruz MAA, Rodrigues JJPC, Al-Muhtadi J, Korotaev VV, de Albuquerque VHC (2018) A reference model for internet of things middleware. IEEE Internet Things J 5(2):871-883. https:// doi.org/10.1109/jiot.2018.2796561

4. de Oliveira JM, Fernandes RCG, Pinto CS, Pinheiro PR, Ribeiro S, de Albuquerque VHC (2016) Novel virtual environment for alternative treatment of children with cerebral palsy. Comput Intell Neurosci 2016:1-10. https://doi.org/10.1155/2016/8984379

5. de Silva RDC, Albuquerque SGC, de V. Muniz A, Filho PPR, Ribeiro S, Pinheiro PR, Albuquerque VHC (2017) Reducing the schizophrenia stigma: a new approach based on augmented reality. Comput Intell Neurosci 2017:1-10. https://doi.org/10. $1155 / 2017 / 2721846$
6. Denis K, Bidet F, Egault J, Gautier A, Coignard P, Rinfray K, Peuziat ML, departe JP, Le-Guiet JL, Morisset N, Pichot N, Bonan I (2016) Utilization of robo-k for improving walking and balance in patients affected by neurological injuries: a preliminary study. Ann Phys Rehabil Med 59:e88. https://doi.org/10. 1016/j.rehab.2016.07.200

7. Fernández C, Baiget P, Roca F, Gonzàlez J (2011) Augmenting video surveillance footage with virtual agents for incremental event evaluation. Pattern Recognit Lett 32(6):878-889. https:// doi.org/10.1016/j.patrec.2010.09.027

8. Gomez-Donoso F, Orts-Escolano S, Garcia-Garcia A, GarciaRodriguez J, Castro-Vargas JA, Ovidiu-Oprea S, Cazorla M (2017) A robotic platform for customized and interactive rehabilitation of persons with disabilities. Pattern Recogn Lett 99:105-113. https://doi.org/10.1016/j.patrec.2017.05.027

9. Guberek R, Schneiberg S, McKinley P, Cosentino F, Levin MF, Sveistrup H (2009) Virtual reality as adjunctive therapy for upper limb rehabilitation in cerebral palsy. In: 2009 Virtual rehabilitation international conference, Haifa, Israel, 29 June-2 July 2009. IEEE. https://doi.org/10.1109/ICVR.2009.5174257

10. Haenggeli CA, Suter-Stricker S (2007) Cerebral palsy. A complete guide for caregiving. In: Miller F, Bachrach SJ (eds) European Journal of Pediatrics, vol second., pp 1311-1311. https://doi.org/10.1007/s00431-007-0457-4

11. Jurdi S, Montaner J, Garcia-Sanjuan F, Jaen J, Nacher V (2018) A systematic review of game technologies for pediatric patients. Comput Biol Med 97:89-112. https://doi.org/10.1016/j.comp biomed.2018.04.019

12. Kerem M, Kaya O, Ozal C, Turker D (2014) Virtual reality in rehabilitation of children with cerebral palsy. In: Cerebral palsychallenges for the future. InTech. https://doi.org/10.5772/57486

13. Khademi M, Hondori HM, McKenzie A, Dodakian L, Lopes CV, Cramer SC (2014) Free-hand interaction with leap motion controller for stroke rehabilitation. In: Proceedings of the extended abstracts of the 32nd annual ACM conference on human factors in computing systems-CHI EA'14. ACM Press. https://doi.org/ $10.1145 / 2559206.2581203$

14. Kirshner S, Blum S, Weiss T, Tirosh E (2009) The meal-maker: a functional virtual environment for children with cerebral palsy. In: 2009 Virtual rehabilitation international conference. IEEE. https://doi.org/10.1109/icvr.2009.5174256

15. Krick J, Miller P (2005) HANDICAP | cerebral palsy. In: Encyclopedia of human nutrition, pp 452-461. Elsevier. https:// doi.org/10.1016/b0-12-226694-3/00250-7

16. Lamb V (2007) Teaching motor skills to children with cerebral palsy and similar movement disorders: a guide for parents and professionals. Pediatr Phys Therapy 19(4):340-341. https://doi. org/10.1097/pep.0b013e31815b5d57

17. Larsen EA (2011) Classification of EEG signals in a brain computer interface system. Master of science in computer science. Norwegian University of Science and Technology, Department of Computer and Information Science. http://daim. idi.ntnu.no/masteroppgaver/006/6288/masteroppgave.pdf?

18. Lloréns R, Colomer-Font C, Alcañiz M, Noé-Sebastián E (2013) BioTrak virtual reality system: effectiveness and satisfaction analysis for balance rehabilitation in patients with brain injury. Neurología (English Edition) 28(5):268-275. https://doi.org/10. 1016/j.nrleng.2012.04.016

19. Lopez-Samaniego L, Garcia-Zapirain B (2016) A robot-based tool for physical and cognitive rehabilitation of elderly people using biofeedback. Int J Environ Res Public Health 13(12):1176. https://doi.org/10.3390/ijerph13121176

20. Lupu RG, Botezatu N, Ungureanu F, Ignat D, Moldoveanu A (2016) Virtual reality based stroke recovery for upper limbs using leap motion. In: 2016 20th international conference on system 
theory, control and computing (ICSTCC). IEEE. https://doi.org/ 10.1109/icstcc. 2016.7790681

21. Neurosky: Mindwave User Guide (2011) http://developer.neu rosky.com/docs/lib/exe/fetch.php?media=mindwave_user_guide. pdf

22. Neurosky: Thinkgear Connector Development Guide (2012) http://developer.neurosky.com/docs/lib/exe/fetch.php?media=think gear_connector_development_guide.pdf

23. Ni L, Fehlings D, Biddiss E (2014) Clinician and child assessment of virtual reality therapy games for motor rehabilitation of cerebral palsy. Arch Phys Med Rehabil 95(10):e105. https://doi. org/10.1016/j.apmr.2014.07.323

24. Oliveira JM, Jorge JCM, Duarte JBF, de Albuquerque VHC (2016) Complementary treatment for children with cerebral palsy based on virtual reality. IEEE Latin Am Trans 14(8):3820-3825. https://doi.org/10.1109/tla.2016.7786369

25. Ravi D, Kumar N, Singhi P (2017) Effectiveness of virtual reality rehabilitation for children and adolescents with cerebral palsy: an updated evidence-based systematic review. Physiotherapy 103(3):245-258. https://doi.org/10.1016/j.physio.2016.08.004

26. Riener R (2015) Virtual reality for neurorehabilitation. Oxford Medicine Online, Oxford. https://doi.org/10.1093/med/9780 199673711.003.0034

27. Rodrigues JJPC, Segundo DBDR, Junqueira HA, Sabino MH, Prince RM, Al-Muhtadi J, Albuquerque VHCD (2018) Enabling technologies for the internet of health things. IEEE Access 6:13129-13141. https://doi.org/10.1109/access.2017.2789329

28. Rose T, Nam CS, Chen KB (2018) Immersion of virtual reality for rehabilitation: review. Appl Ergon 69:153-161. https://doi. org/10.1016/j.apergo.2018.01.009

29. Wallon $H$ (1972) The psychological development of the child. Int J Mental Health 1(4):29-39. https://doi.org/10.1080/00207411. 1972.11448595

30. Wang M, Reid D (2011) Virtual reality in pediatric neurorehabilitation: attention deficit hyperactivity disorder, autism and cerebral palsy. Neuroepidemiology 36(1):2-18. https://doi.org/ $10.1159 / 000320847$

31. Weightman MM, Bolgla R, McCulloch KL, Peterson MD (2010) Physical therapy recommendations for service members with mild traumatic brain injury. J Head Trauma Rehabil 25(3):206-218. https://doi.org/10.1097/htr.0b013e3181dc82d3

32. Zhang $\mathrm{T}$, rong Wang $\mathrm{Z}$, Wang $\mathrm{P}$, Xing L, ping Mei L, Zhao J (2017) Leap motion-based virtual reality training for improving motor functional recovery of upper limbs and neural reorganization in subacute stroke patients. Neural Regen Res 12(11):1823. https://doi.org/10.4103/1673-5374.219043

Publisher's Note Springer Nature remains neutral with regard to jurisdictional claims in published maps and institutional affiliations. 